\title{
On the Possibility of Hallucinations
}

Farid Masrour

University of Wisconsin-Madison
masrour@wisc.edu

On relationalism, mind-independent external objects are constitutive components of veridical perceptual experiences (Brewer 2007, 2011; Campbell 2002, 2011; Martin 2002, 2004, 2006, McDowell 1994, and Fish 2009). ${ }^{1}$ Relationalists argue that the view cures many philosophical ills; it fends off the threats of skepticism (McDowell 1982, 1994, 2008), explains knowledge of demonstrative reference (Campbell 2002), explains the phenomenal character of experience (Fish 2009), saves us from an error theory of experience (Martin 2002), and explains our categorical grasp of ordinary mind-independent objects (Brewer Ibid. Campbell Ibid., Campbell and Cassam 2014). Despite its proclaimed advantages, however, philosophers have not converted to relationalism in flocks. One reason for this is some degree of skepticism about the advertised merits of the view (Campbell and Cassam Ibid., Casssam 2011, Levine 2010, Rey 2005, Wright 2002, 2008; Williamson 2000). But another reason is disenchantment with the standard relationalists response to the argument from hallucination. ${ }^{2}$ One version of this argument, put roughly, goes as follows. Some possible hallucinations are phenomenally indistinguishable from veridical perceptual experiences, and therefore have the same metaphysical nature as veridical perceptual experiences. But hallucinations are not constituted by relations to mind-independent objects. Thus, veridical perceptual experiences are not constituted by relations to mindindependent objects either. ${ }^{3}$

Relationalists commonly react to this argument by embracing disjunctivism. They accept the possibility of hallucinations that are phenomenally indistinguishable from perceptual experiences, but deny that hallucinations and veridical perceptual experiences have a common metaphysical nature (Campbell 2002, Fish 2009, Hinton 1967, 1973; Martin 2004, McDowell 1982, and Snowdon 1980). ${ }^{4}$ This move is often supported by noting that unlike phenomenal identity, phenomenal indistinguishability is a non-transitive relation. There can be series of experiences E1, .., En where E1 and En are discernible but each member of the series is phenomenally indistinguishable from its adjacent members. Thus, phenomenal indistinguishability is not a transitive relation and does not entail type identity. Relationalists thus resist the move from a premise about the nature of hallucinations to a

\footnotetext{
${ }^{1}$ Some of these authors characterize their view in terms of relations to items such as facts or the layout of the environment. But since objects are constitutive components of such items, I shall assume that these authors are committed to relationalism as defined here. Also, not all of these authors describe themselves as relationalists. "naïve realism", "direct realism" and "disjunctivism" are other common labels for views that entail relationalism.

2 This is often implicit. But see Sturgeon 1998, and Hawthorne and Sturgeon 2006 for explicit discussion.

${ }^{3}$ See Soteriou 2016 for an excellent discussion of other versions of the argument from hallucination.

${ }^{4}$ Not all versions of disjunctivism are formulated in terms of the nature of the states in question. For discussion see Byrne and Logue 2008 and Soteriou 2014.
} 
conclusion about the nature of veridical perceptual experiences by denying that the indistinguishability of hallucinations implies sameness of their nature.

However, disjunctivism may not be the best defensive strategy for the relationalist. For one thing, it is not clear that the distinction between phenomenal identity and introspective indistinguishability can block all versions of the argument from hallucination. Let us say that two experiences are weakly indistinguishable when they cannot be introspectively discerned by a normal subject who possesses all the relevant discriminatory capacities. We can contrast weak indistinguishability with strong indistinguishability, where two experiences are strongly indistinguishable when they are weakly indistinguishable and any experience that is weakly indistinguishable from one is weakly indistinguishable from the other. Strong indistinguishability is a transitive relation. Thus, the opponent of relationalism can simply rewrite the argument from hallucination as an argument about the possibility of hallucinations that are strongly indistinguishable from veridical perceptual experiences.

A second problem with the disjunctivist move is that accepting the possibility of hallucinations clashes with some of the positive reasons that relationalists offer in support of their view. For example, relationalists often cite the transparency of veridical experience as supporting their view. But it is unclear how this claim coheres with the indistinguishability of some hallucinations from veridical experiences. Are such hallucinations transparent? If they are then the support that transparency provides for relationalism is significantly weakened. If they are not then transparency does not seem to be a feature that is knowable by introspection. ${ }^{5}$ Both of these implications would weaken the support that transparency allegedly provides for relationalism.

Of course, the relationalist could respond by insisting that strong indistinguishability does not entail phenomenal type identity and/or denying that introspective knowability requires the satisfaction of a safety condition. ${ }^{6}$ But the point here is not that disjunctivism is implausible. The point is that the appeal to disjunctivism is dialectically suboptimal. Denying that strong indistinguishability entails phenomenal identity without supporting reasons would be ad hoc and denying the safety condition over introspective knowledge is dialectically undesirable. Relationalists would therefore benefit from considering nondisjunctivist responses to the argument from hallucination. Sketching such a response is my main aim in this paper.

\footnotetext{
${ }^{5}$ By the transparency of experience, I mean the intuitive sense in which in having experience we seem to be presented with external objects and their qualities as opposed to experiences and their intrinsic qualities. There is a continuing debate about the best way to further articulate this intuitive point and whether and how it supports relationalism. But, arguably, my point here about the relationship between disjunctivism and the evidential role of transparency applies independently of the outcome of this debate.

${ }^{6}$ An alleged mechanism for belief formation, $\mathrm{K}$, satisfies the safety condition when it is impossible for $\mathrm{K}$ to give rise to a belief $\mathrm{P}$ when $\mathrm{P}$ is false. One who denies that introspective knowability requires safety could deny that hallucinations are transparent without threatening the knowability of the transparency of veridical experiences through introspection.
} 
My proposal, simply put, is that one can resist the arguments in support of the possibility of hallucinations that are strongly indistinguishable from veridical perceptual experiences. I would like to examine the prospects of defending the following thesis that I call Objectual Realism:

\section{Objectual Realism}

Necessarily, there are no perceptual experiences without a mind-independent external natural object that is their perceptual object.

As a working definition, by a perceptual experience I mean an experience that is strongly indistinguishable from a possible human veridical perceptual experience. In what follows, I drop the qualifier 'strongly introspectively' and simply use 'indistinguishable'. So, from now on, when I say that two experiences are phenomenally indistinguishable I mean that they are strongly indistinguishable under introspection. Characterizing perceptual experiences in terms of their relation to veridical perceptual experiences implies that any hallucinations, in so far that they satisfy this condition, would count as perceptual experiences. ${ }^{7}$ Therefore, Objectual Realism is not true by definition. By a mindindependent object I mean one that exists independent of a mental attitude and by an external natural object I mean a posit of natural sciences that is external to the boundaries of the nervous system. The question as to what perceptual objects are is at the core of our topic. For our purposes now, it suffices to say that a perceptual object is often the object that fills the gap in perceptual reports such as 'I saw ...', 'I heard ...'. ${ }^{8}$

People report having had hallucinations. Medical science, neuroscience and psychology not only accept the occurrence of hallucinations but also use them to taxonomize psychotic disorders. Investigating the mechanisms underlying hallucination also forms a good part of respectable research in these disciplines. Should we conclude that the Objectual Realism is in conflict with common sense and empirical science? No. This conflict is only apparent. On one construal, a hallucination is a perceptual experience that does not have a natural mind-independent object as its perceptual object. We can call this the metaphysical sense of hallucination or m-hallucination for short. Objectual Realism is incompatible with the possibility of $\mathrm{m}$-hallucinations. However, it is not clear that common sense and empirical sciences are committed to the possibility of m-hallucination. On a second construal, a hallucination is a perceptual experience that normally, and in the absence of contrary evidence, directly causes a belief in the existence of an object that is not the object of the experience. We can call this the doxastic sense of hallucination or d-hallucination for short. We can explain the role of hallucinations in common sense and empirical science simply in terms of a commitment to the occurrence of d-hallucinations. In so far as common sense and empirical sciences are committed to the possibility of d-hallucinations, they are compatible with Objectual Realism.

\footnotetext{
7 Siegel 2004 and Johnston 2004 have argued against the view that all perceptual experiences are phenomenally distinguishable from a veridical perceptual experience. Whether this is a problem for the definition used here, depends on how we understand 'possible' in 'possible veridical experience'. But this issue has no bearing on my arguments here. So, I will not pursue it further. ${ }^{8}$ I shall argue soon that in some cases the perceptual object of an experience is not what fills the gap in such reports.
} 
Defending Objectual Realism does not amount to establishing relationalism. For, it is one thing to show that all possible perceptual experiences have mind-independent natural objects and it is another thing to show that these objects are constitutive components of perceptual experiences. Nevertheless, defending Objectual Realism blocks the argument from hallucination by denying what relationalists and their opponents both accept: the idea that m-hallucinations are possible. Defending Objectual Realism therefore enables us to adopt a non-disjunctivist version of relationalism. ${ }^{9}$

The goal is to explain four strategies to resist the common reasons that are offered for accepting the possibility of hallucinations. I have devoted one section to each strategy. But, since the discussion of each strategy is lengthy and dense, the first section previews the four strategies. Sections two through six then develop these strategies in more detail. The discussion is structured on a rough taxonomy of the alleged evidence in favor of the possibility of hallucinations. Sections two and three focus on arguments that draw on behavioral evidence, section four on arguments from neuroscience and section five on conceivability arguments. Each strategy consists in explaining a type of response to these arguments and arguing that current evidence does not rule out this response. The conclusion of the paper is that there are promising paths for resisting the main arguments for the possibility of m-hallucinations. The proponents of Objectual Realism can therefore retain their ground and relationalists have a non-disjunctivist response to the argument from hallucination. A corollary upshot is that whether hallucinations are possible is an open empirical question. For, whether we have good evidence for the possibility of mhallucinations depends on some yet uninvestigated empirical questions. I briefly discuss these questions in the concluding section of the paper.

Before continuing, let me note that this paper belongs to an emerging literature on nondisjunctivist responses to the argument from hallucination. ${ }^{10}$ But there are significant

${ }^{9}$ An additional thesis that is often held alongside relationalism is the thesis that the phenomenal character of veridical perceptual experiences is, at least partly, constituted by the properties of their perceptual objects. Those relationalists who embrace this additional thesis need to also respond to arguments from illusion, where illusions have perceptual objects but do not present them as they are. Accepting relationalism in the way defined here, however, does not force us to accept the additional thesis about the constitutive relation between the properties of external objects and the phenomenal character of perceptual experience. Therefore, I am not concerned with the argument from illusion here. My own view is that the correct account of the nature of perceptual experience is an account that accepts relationalism but denies that properties of objects are constitutive components of the phenomenal character of perceptual experiences. I call this view minimal externalism. On minimal externalism, external objects are constitutive components of perceptual experiences. However, what distinguishes the phenomenal character of one experience from another experience depends only on the non-relational properties of the subject of experience. The view thus synthesizes the realist intuition that perceptual experience directly connects us to the world with the internalist intuition that the phenomenal character of perceptual experience is determined, for the most part, by what goes on inside the boundaries of the head.

${ }^{10}$ Langsam 1997 and Alston 1999 mention, in passing, such responses, though they neither develop nor adopt them. More recently, Raleigh 2014 and Ali 2017 have defended strategies that partially overlap with some of the strategies that I develop here. Some authors have also defended 
differences in goals, substance, degree of comprehensiveness, and the level of analysis between what I suggest here and what has been previously discussed. I shall comment on some of these differences in the relevant sections. But to highlight a central difference, the goal of the recent non-disjunctivist literature has been to defend the general thesis that all hallucinations have objects. ${ }^{11}$ My goal differs in two respects. First, my primary concern is the status of the evidence for the possibility of m-hallucinations. The goal is to argue that the alleged empirical and a priori evidence in support of the possibility of m-hallucinations is inconclusive. This has the corollary upshot that whether such hallucinations are possible or not is still an open empirical question. Second, I do not think that m-hallucinations form a single kind that admits of a uniform treatment. As I'll argue, some such cases might be illusions, some might be veridical perceptions and some might be phenomenally distinguishable from veridical perceptions and therefore fail to count as perceptual experiences. So, I shall not be arguing for a uniform positive account of hallucinations.

\section{The Four Strategies}

The idea that hallucinations are possible is based on a mixed body of evidence including empirical observation and armchair reasoning. My strategy combines four generic replies to this alleged evidence. I call these replies Displacing, Denial, Anchoring, and Dependence. This section introduces these replies by illustrating their application to four examples. The next sections develop each reply in more detail.

Consider John who, after taking a hallucinogen, reports seeing a pink elephant in the corner of his room, where there is, in fact, no pink elephant. The orthodox description is that he is m-hallucinating. On an alternative construal the correct characterization of how things visually appear to John is that the room appears to have a specific property, a property whose appearance is very similar to and therefore easily mistaken with the appearance of a pink elephant in the corner of the room. This way of thinking about John's situation, in effect, re-describes the experience of the elephant as a way in which the room is experienced. I call the general strategy that is exemplified here Displacing. In Displacing, an aspect of experience that is taken to be presenting a non-existent object is re-described as misrepresenting a property of a perceived external concrete particular. The re-description turns what we regard as a hallucination into an illusion. So, Displacing is a potential way to explain away the claim that an experience is a hallucination. There is more to say about this strategy and the conditions in which it is viable. But before doing so, let me introduce the other strategies.

particular account about specific cases that, though not aimed at mounting non-disjunctivist defenses of relationalism, have the implication that some alleged cases of $\mathrm{m}$-hallucinations are not hallucinations. See, for example, Chalmers 2005, Gallagher \& Zahavi 2012 and Thompson \& Cosmelli 2011 who defend the view that subjects in some envatment scenarios are not hallucinating. I will be developing this line in detail in section 4.

${ }^{11}$ Raleigh and Ali both set their goal to defend the view that all hallucinations have objects. Ali has the further thesis that that all hallucinations are illusions and thus calls his view illusionism. 
Consider John again. This time, he reports dreaming of a pink elephant in the corner of his room during his sleep. The dream, John reports, was extremely vivid and similar to a normal perception. Some might be inclined to think that John's dream is an mhallucination. For, John's dream is both phenomenally indistinguishable from a veridical perceptual experience of a pink elephant and objectless. Here, Displacing would not work because there is no external object to serve as the object of John's experience. In general, Displacing would not work for explaining away allegedly internally generated hallucinations. However, it is possible to deny that John's dream is phenomenally indistinguishable from a possible veridical experience of a pink elephant. If so, then the dream would not be a hallucination of a pink elephant. I call this strategy Denial and shall elaborate on it in section three.

In the third case, John is a brain in a vat, hooked to a super-computer that stimulates his brain in a manner that gives rise to an experience that is phenomenally indistinguishable from a veridical experience of a pink elephant. Some might be inclined to regard John's experience as objectless and therefore an m-hallucination. Here again, Displacing is not available because John is not having a hallucination of an item in a scene that he is otherwise perceiving correctly. Denial is also unavailable because John's experience is, by assumption, phenomenally indistinguishable from a veridical perceptual experience. However, we can regard the activity in the super-computer that causes and maintains the neural correlate of John's experience as its object. If so, John's experience would not be a hallucination. I shall call this strategy Anchoring. ${ }^{12}$

The three strategies that I have so far discussed explain away empirical evidence to the effect that m-hallucinations actually happen or are empirically possible. But one might give a direct argument for the metaphysical possibility of m-hallucinations that relies neither on their actuality nor their empirical possibility. Let us consider a scenario in which John is a disembodied mind undergoing a random string of conscious experience that is phenomenally identical with a veridical experience of a pink elephant. Since there are no external objects in this scenario neither Anchoring nor Displacing would help. Moreover, John's experience is, by assumption, phenomenally identical with a possible veridical experience. Therefore, Denial would not be of help either. So, if this scenario is metaphysically possible then m-hallucinations are metaphysically possible. Furthermore, it might be argued that such a scenario is metaphysically possible, because it is conceivable and conceivability entails metaphysical possibility. Hence, m-hallucinations are metaphysically possible. ${ }^{13}$

One might be inclined to respond to the above argument by denying the link between conceivability and possibility. However, it is possible to resists the argument without doing so. Conceivability arguments are often regarded as a priori arguments that are independent from empirical assumptions. But I shall argue that the idea that scenarios such as the above

\footnotetext{
12 It is possible to even resist the idea that John's experience is an illusion. For a defense of the view that in some envatment scenarios experiences are not illusory see Chalmers 2005.

${ }^{13}$ Kriegel 2013 envisions a scenario like this that he calls the "space soul" scenario. Rather than giving an argument for the possibility of hallucinations, however, his goal is to distinguish between two senses of intentionality.
} 
are conceivable presupposes that either hallucinations actually happen or are empirically possible. The argument could therefore be blocked by blocking the empirical arguments for the possibility of hallucinations. Since the core move is to show that the conceivability of m-hallucinations depends on presupposing their actuality or empirical possibility, I call the strategy Dependence. In conjunction with the previous strategies, Dependence can help us block the conceivability arguments for the possibility of hallucinations without denying that conceivability entails metaphysical possibility.

I have introduced four strategies for blocking common arguments for the possibility of mhallucinations. Displacing and Anchoring accept the possibility of certain alleged cases of hallucination but re-describe them as illusions. Denial accepts that certain experiences might be object-less but denies that they are m-hallucinations by denying that such experiences are perceptual experiences. Dependence shows that the idea that $\mathrm{m}$ hallucinations are conceivable depends on the empirical reasons for the possibility of hallucinations and could therefore be blocked by blocking these reasons. It is my contention that, when combined, these strategies can help the relationalist resist the possibility of mhallucinations. This rejection does not require arguments to the effect that hallucinations are impossible. It consists in defensive moves against arguments for the possibility of hallucinations. ${ }^{14}$ The forthcoming sections develop these strategies in more detail.

\section{Displacing and Embedded Hallucinations}

John takes a hallucinogen and reports seeing a pink elephant while staring at the bare corner of his room. He comes to believe that a pink elephant is there. There is no denial that cases like this happen. In fact, cases of this sort are one of the main reasons that ordinary folk and people in the behavioral and medical sciences believe that hallucinations actually happen. But when I say that cases like this happen, I mean that there is no denial that people, as a result of exposure to certain drugs or episodes of psychosis, undergo experiences that lead them to believe that they are perceptually encountering certain objects, where these objects do not exist. In other words, it is uncontroversial that dhallucinations occur. What is not clear, however, is whether John is having an mhallucination, that is, whether he is having an objectless perceptual experience. If we can resist the idea that these cases are objectless experiences, then we have explained away the reason that their possibility gives us for accepting the possibility of hallucinations.

One feature of John's situation is that his experience presents the non-existent pink elephant as embedded within a scene and John correctly perceives the other elements in this scene. We can say that John is having an embedded hallucination. The fact that John's experience is embedded opens the possibility of explaining away the claim that John is having an mhallucination by relying on a strategy that I earlier called Displacing. On this response, the object of John's experience is the room. The aspect of John's experience that corresponds to the pink elephant is re-described as corresponding to a property that he experiences the

14 Positive arguments against the possibility of hallucinations can be based on the reasons that one might have for embracing a relationalist conception of experience. I shall not discuss these arguments here. 
room as having. As a working characterization, in Displacing, an aspect of experience that is taken to be presenting a non-existent object is re-described as misrepresenting a property of a perceived external concrete particular. The re-description turns what we regard as a hallucination into an illusion. ${ }^{15}$

Before scrutinizing this strategy, let us step back and consider a simpler case. Here is a partial description of the content of my visual experience.

My desk seems to have a roughly oval discoloration in the middle. The discoloration has a grayish yellow hue that contrasts with the brown of the rest of the desk.

The above description switches back and forth between treating the discoloration as an object and treating it as a property of the desk. In "My desk seems to have a roughly oval discoloration in the middle", "discoloration" figures as part of a predicate phrase that attributes the property of having an oval discoloration to the desk. In "The discoloration has a grayish yellow ...", "discoloration" figures as a noun. We can say that with respect to the discoloration the first sentence is property-indicative and the second sentence is objectindicative. Two points about this distinction are in order.

First, the choice between object-indicative and property-indicative descriptions of content is not arbitrary. The phenomenal character of our everyday experiences typically has a dimension that corresponds to the distinction. In other words, there is something that it is like to experience something as an object and something that it is like to experience something as a property. ${ }^{16}$ Building on this point, we can say that ordinary experience has a phenomenal objectual structure that determines which of its aspects correspond to phenomenally presenting objects and which aspects do not. A correct description of the phenomenal content of an experience has to respect its phenomenal objectual structure in that it should describe those aspects of the experience that correspond to phenomenally presenting objects in an object-indicative manner.

Second, whether my experience is an illusion or an m-hallucination partly depends on its objectual phenomenal structure. Suppose that there is actually no discoloration on the surface of the desk although it seems to me that there is. If the correct characterization of the content of my experience should be object-indicative then I am having an mhallucination; and if it should be property-indicative then I am having an illusion. In general, whether an experience is an m-hallucination or an illusion is partly a matter of its objectual phenomenal structure.

The above two points motivate an important question about John's situation and other reports of embedded hallucinations. The question is whether John's report is faithful to the

\footnotetext{
15 Langsam 1997 discusses a view on which some hallucinations can be regarded as relations to the empty space around the subjects. As I'm using the term, the empty space around us does not qualify as a concrete particular. So Langsam's proposal would not satisfy our working characterization of Displacing.

16 This is of course a substantive claim but I assume it without argument.
} 
objectual phenomenal structure of his experience, at least that aspect of his experience that John describes as the experience of the pink elephant. This question could get a negative answer in two different ways. First, the phenomenal objectual structure of an experience might be indeterminate with respect to the aspect that he describes as the experience of the pink elephant. ${ }^{17}$ Alternatively, the phenomenal objectual structure of John's experience might be determinate but the correct description of its aspect pertaining to the pink elephant should be property-indicative. In neither of these cases would John's report be faithful to the phenomenology of his experience. More importantly, John's experience would be an illusion, not an m-hallucination. In general, people's reports of their allegedly embedded hallucinations might fail to faithfully reflect the phenomenal objectual structure of their experiences in similar ways. If so, these experiences would be illusions, not mhallucinations.

Many factors can explain why people's reports might fail to faithfully reflect the phenomenal objectual structure of their experience. For one thing, people might fail to correctly access the content of their experiences, store them in memory, or report them exactly because they are influenced by hallucinogens or are undergoing an episode of psychosis. But there are other causes. One might misreport one's experience because one is not paying attention to subtle differences or lacks the relevant skills. Also, people's reports are partly shaped by their implicit or explicit assumptions about what is relevant and significant in their communicative context. In many everyday contexts, the distinction between the property-indicative and the object-indicative modes of describing the hallucination is simply unimportant. Thus, people might report an aspect of their experience that does not present an object in an object-indicative mood not because they are mistaken about their experience, but simply because the distinction does not matter in their communicative context and the object-indicative mood is more convenient. It would indeed be surprising if verbal reports always faithfully reflected the content of experience in uncontrolled conditions.

Let us take stock of the discussion so far. One type of evidence for the possibility of mhallucinations consists in reports of the occurrence of embedded d-hallucinations. But reports of d-hallucinations can fail to faithfully capture their phenomenal objectual structure. This can happen in two ways. Sometimes the report might misrepresent the determinate objectual structure of an experience. Sometimes it might misrepresent an experience that has a partially indeterminate objectual structure as having a determinate structure. These observations put us in the position to characterize Displacing in a more accurate way. On Displacing that the experience in question does not have the objectual structure that it is reported to have and when we accurately consider its objectual structure

\footnotetext{
17 Second, the phenomenal objectual structure of an experience can be partially indeterminate. The experience of the discoloration is an example of this. In those cases where my description treated the discoloration as an object (or a property), I could have used another description in which the discoloration would have figured as a property (or an object) and I could do so without feeling that my description was unfaithful to my experience. Arguably, the phenomenal objectual structures of many of our everyday experiences are partially indeterminate in the same way.
} 
we can see that all of its objects are in fact present in the environment. ${ }^{18}$ Almost everything said here about reports generalizes to other behavioral evidence such as experience-guided action. Displacing is therefore a strategy to resist the idea that the behavioral evidence for the occurrence of embedded d-hallucinations is good evidence for the occurrence of embedded m-hallucinations.

It is important to note that the point is not that we would not have good evidence for the occurrence of an embedded m-hallucination unless we have determined the objectual structure of an embedded d-hallucination with certainty. The point is cautionary and programmatic. Determining the objectual structure of an experience is an empirical project that consists in weighting empirical evidence. Of course, a subject's report and behavior is relevant and in normal conditions counts as good evidence. But the evidential value of report and behavior is very low in many conditions including conditions where subjects are hallucinating, remembering past hallucinations, lack sensitivity to subtle differences, or find the differences irrelevant to their communicative intentions. Empirical science does not demand certainty but this does not mean that it gives up the demand for proper design and controls. In such conditions, alternative explanations need to be ruled out by proper experimental design and this, as far as I know, has not been done in the case of hallucinations. ${ }^{19}$ The main upshot of this section is therefore that whether embedded mhallucinations occur or not is simply a question that has not been carefully studied by methods that meet the standards of behavioral disciplines.

\section{Denial, Dreams and other Internally-generated Experiences}

\footnotetext{
${ }^{18}$ In the course of his discussion of Macbeth's dagger hallucination, Alston 1999 mentions a possible response according to which the air surrounding the dagger is the object of the experience. Alston says about this proposal that 'Whenever we have ... [a] visual hallucination, in which the hallucinatory object(s) is (are) embedded in a veridically perceived setting, the visually hallucinated object(s) will appear to be located somewhere in front of the perceiver. Since there will always be something physical in that region, that something can be taken as what looks to the perceiver to be radically other than what it is.' (Ibid, p. 191). Although he ends up abandoning this proposal in favor of the view that hallucinations consist in relations to mental objects, it is instructive to see how the proposal differs from Displacing. According to the strategy that Alston discusses, the only constraint is the presence of the object in the right location in the subject's environment. On Displacing, in contrast, the switch to the present object is permissible only in those cases where the experience in questions has the appropriate objectual unity structure. As a result, in many cases where Alston' strategy is applicable, Displacing is not available. In fact, I find Alston's proposal implausible exactly because it does not respect the constraints that the phenomenal character of experience should impose on what can be regarded as the object of an experience.

19 The reason for this is simple. The distinction between d-hallucinations and $\mathrm{m}$-hallucinations that is at the core of our issue has been irrelevant to the goals of most of the empirical sciences that have studied hallucinations. To give an example, the occurrence of third-person auditory hallucinations is important evidence for schizophrenia. But a psychiatrist who wants to diagnose a case does not care whether a reported auditory third-person hallucination is an m-hallucination or merely a d-hallucination.
} 
In our second example, John dreams of a pink elephant and later reports that his dream was indistinguishable from a normal perceptual experience. The report, might be regarded as good evidence for the occurrence of m-hallucinations. If John's dream is phenomenally indistinguishable from a veridical experience it would count as a perceptual experience and, lacking an external object, an m-hallucination. This can be generalized to all cases of internally generated experiences that are allegedly phenomenally indistinguishable from veridical perceptual experience, including experiences resulting from psychosis or hallucinogens, iconic memories, and some cases of imagination.

Earlier, I called the strategy of denying that an experience is phenomenally indistinguishable from possible veridical perceptual experiences Denial. Like the case of Displacement, the viability of Denial is grounded in the fact that subjective reports are not always reliable indicators of phenomenal character. Specifically, there can be many respects in which an experience might be phenomenally distinguishable from a veridical experience where subjective reports do not reflect this distinguishability. Let me elaborate with an example. This will also help us characterize Denial in a more precise way.

An afterimage as of a green triangle is similar to a veridical experience of a green triangle in that it has a visual quality and a rich content. However, an afterimage of a green triangle is phenomenally distinguishable from a veridical perceptual experience of a green triangle. A veridical experience of a green triangle typically exhibits the phenomenon of constancy. For example, when you get closer to the triangle, although the triangle would occupy a larger portion of your visual field, you would not experience it as increasing in size. If the triangle rotates in its place, the shape of its projection on your retina will change, but you would not experience the triangle as changing its shape. The same could be said about many other properties of the triangle. ${ }^{20}$ But these dynamic constancy patterns are absent in the case of the afterimage. Despite its similarity to a veridical experience of a green triangle, the after-image has a phenomenal character that is distinguishable from a veridical experience. Arguably, phenomenal constancy is an essential phenomenal feature of perceptual experience. If so, afterimages are phenomenally distinguishable from any possible perceptual experience. ${ }^{21}$

Constancy may not be the only essential phenomenal feature of perceptual experience. Other features such as vividness, saturation, determinacy, and phenomenology of presence are candidate features that might be essential for perceptual experience. Let us call the set of phenomenal features that are essential for perceptual phenomenology perceptual phenomenal markers. We can call experiences that are similar to veridical perceptual experiences in exhibiting distinctively sensory qualities such as visual, tactile or auditory qualities but lack some perceptual phenomenal markers pseudo-perceptual experiences. According to Denial, our subjective evidence does not rule out the hypothesis that dreams and other internally generated experiences are pseudo-perceptual. An after image, for example, is a pseudo-perceptual experience. But reports of afterimages, often fail to reflect the phenomenal differences between afterimage experiences and experiences of ordinary

20 See Burge 2010 and Masrour 2013 for a defense.

${ }^{21}$ For a discussion of the phenomenal character of afterimage experiences see Siegel 2006 and Masrour Ibid. 
objects. This can have many reasons including lack of introspective skills, lack of attention, and the demands on the communicative context. The same applies to report of dreams. Moreover, reports of dreams are based on memory and it is unclear whether the relevant differences are registered in memory. Subjective reports of dreams are therefore unreliable at the level that is relevant to the distinction between perceptual experiences and pseudoperceptual experiences. The case for the reliability of subjective reports gets only worse when we consider reports of hallucinogen-induced and psychosis-induced internally generated experiences. In general, it is not clear that current subjective evidence regarding internally generated experiences favors the hypothesis that these experiences are phenomenally indistinguishable from veridical perceptual experiences over the hypothesis that they are pseudo-perceptual. If so, Denial is a viable response to arguments that draw on such evidence. ${ }^{22}$

Here again, the point is not that we do not have good evidence for the occurrence of an internally generated m-hallucination unless we have ruled out with certainty that the experience is pseudo-perceptual. The point is that we do not have good evidence according to the evaluative criteria that are implicit in the practice of empirical science. If you ask a psychologist whether there is good evidence that people sometimes dream of elephants she will tell you that there is ample evidence for that. But if you then explain the distinction between perceptual and pseudo-perceptual experiences and ask whether there is good evidence that people's elephant dreams are perceptual as opposed to pseudo-perceptual, she will very likely tell you: 'The question has not been studied. So, No. there isn't much evidence for that yet!'

\section{Anchoring and Neural Evidence}

John is a brain in a vat, hooked to a super-computer, experiencing a pink elephant in what seems to be the corner of his room. One might argue that as there is no elephant in the room, John has an object-less experience, hence an m-hallucination. Since empirical science tells us that cases like this are nomologically possible it also tells us that mhallucinations are possible. My goal in this section is to defend the Anchoring response to

22 The idea that dreams differ in their phenomenal character from normal wakeful experiences is not new. Different versions of this idea range from outright denial that dreams are experiences to views that identify specific respects in which dreams differ from wakeful perceptual experiences. Malcolm 1956 and Dennett 1976, for example, deny that dreams are experiences. On the more specific side, Sartre 1940 and Hering 1947 hold that dreams are experienced as fictions. McGinn 2004 argues that dreams lack the phenomenology of presence. James 1890, Stone 1984, McGinn

Ibid, and Ichikawa 2008 hold that dreams lack saturation and determinacy. Noë 2004 defends the view that dream experiences fail to satisfy sensory-motor contingency laws. These views are complemented by various forms of skepticism about the reliability of dream reports and imaging data that suggests similarities in neural activation between dream and sleep. See Harley 2004, Colthear 2006, and Klein 2010a, b for skeptical views about drawing psychological conclusions from neuroimagery data. See also Austin 1962, 48-9, Schwitzgebel 2011 and Rosen 2013 for defenses of the view that dream reports are unreliable. On the side that dreams are phenomenologically very similar to wakeful experiences see Revonsuo 2006, Hobson 1988 and Hobson et al.2000. 
arguments of this sort. On the Anchoring strategy, the object of John's experience is some part of the super-computer whose activity is responsible for maintaining John's brain activity. Let us call this part of the super-computer Pinky. ${ }^{23}$ According to Anchoring, John's experience is not an m-hallucination because it has Pinky as its object. ${ }^{24}$

The intuition that motivates Anchoring is that Pinky's role in generating John's experience is similar to the role that ordinary objects play in generating ordinary experiences. But admittedly, the idea that Pinky is the object of John's experience is also intuitively discomforting. In what follows I shall show that this latter intuition does not stand up to further scrutiny. I do so by introducing and then rejecting several ways that we might support this intuition by grounding it in general principles. Here is the first one.

\section{Causal Path}

Something is the object of an experience only if it belongs to the causal chain that goes through the subject's normal perceptual apparatus. But the causal chain from Pinky to the brain activity does not go through John's normal perceptual apparatus. Therefore, Pinky does not perceptually appear in John's experience.

Suppose Patrick is hit on the head by a rubber mallet and starts seeing star-like flashes. We would not want to say that the mallet is the object of Patrick's experience. One way to account for this intuition is that the causal link between the mallet and Patrick's experience does not go through his normal perceptual apparatus. The argument in Causal Path generalizes this intuition to John's case. Since John does not use his eyes to have the pink elephant experience, the causal chain that links Pinky to John's experience does not go through his normal perceptual apparatus.

However, it is not clear why we should accept the premise that something is the object of a perceptual experience only if it belongs to a causal chain that goes through one's normal perceptual apparatus. One reason that might be given in its support is that when something does not affect us through our normal perceptual apparatus, then even if it results in some sort of experience, the resulting experience is not a perceptual experience. But this would conflict with the idea that every experience that is phenomenally indistinguishable from a perceptual experience is a perceptual experience. As we saw earlier, rejecting this assumption opens up the possibility of a disjunctivist reply to the argument from hallucination. Thus, this is not an assumption that our interlocutor would want to reject. But if so, it is not clear why when something gives rise to a perceptual experience we can simply disqualify it from perceptually appearing just because its causal impact does not go through our normal perceptual apparatus. Thus, the main premise of Causal Path is undermotivated. Moreover, there are better explanations for the intuition that the rubber mallet

${ }^{23}$ For similar views about the brain in a vat cases see Chalmers 2005, Gallagher \& Zahavi 2012, Thompson \& Cosmelli 2011, Raleigh 2014, and Ali 2018.

${ }^{24}$ A further question is whether John's experience is an illusion or a veridical experience. Opinions can differ here. Chalmers 2005, for example, argues that some brain in a vat cases are not even illusions. But we do not have to settle this issue to pursue Anchoring. What matters is whether these are cases of m-hallucination or not. 
is not the object of Patrick's perceptual experience, though these explanations do not withstand scrutiny either. Here is another one.

\section{Veridicality}

Something is the object of an experience only if some of its qualities veridically appear in experience. But none of the qualities of Pinky veridically appear in John's experience. Therefore, Pinky is not the object of John's visual experience.

The first premise of Veridicality is that something visually appears only if some of its qualities veridically appear. However, it seems plausible that something can appear although none of its qualities veridically appear. So, it is unclear why we should accept the first premise. ${ }^{25}$

The second premise can be challenged too. Consider night vision goggles that transform heat-generated infrared waves from the surface of objects into a visible green color pattern. There is also an intuitive sense in which the goggles are assessable for accuracy. For example, if a non-uniformly heated surface appears uniformly green, then the goggles are not performing accurately. There is therefore a sense in which we can regard some ways in which the goggles make heat visible veridical and some non-veridical. Analogously, there is an intuitive sense in which some ways that Pinky appears can be regarded as veridical and some as non-veridical. If so, there is a sense in which some of the qualities of Pinky might be appearing veridically in John's experience. Therefore, we can reject the second premise of Veridicality too.

A third way to try to account for the intuition that Pinky is not the object of John's experience is to appeal to visibility.

\section{Visibility}

Something is the object of a visual experience only if some of its visible qualities appear in experience. But none of the visible qualities of Pinky appear in John's experience. Therefore, Pinky is not the object of John's visual experience.

When we see something, we see some of its visible qualities. This, one might argue, motivates the idea that something is the object of one's visual experience only if some of its visible qualities appear in visual experience. According to Visibility, although some of the qualities of Pinky appear in John's experience, these qualities are not the visible qualities of Pinky. Therefore, Pinky does not visually appear because none of its visible qualities appear.

However, we can block Visibility by distinguishing between two senses of a visible quality. Under one sense, a quality is visible only if it can be seen by normal perceivers in normal

${ }^{25}$ See Ali 2017 for an extended discussion of a veridicality requirement. 
conditions of observation. ${ }^{26}$ This sense of visibility conforms well with our everyday use of the predicate 'visible'. We say, for example, that properties such as colors and shapes are visible but infra-red light and magnetic fields are not. Let us call this the narrow sense of visibility. Under this sense, it would be correct to deny that the visible qualities of Pinky appear in John's experience, because such qualities, for example, the gross shape or color of the silicon circuits that make up Pinky, do not appear in John's experience. Those qualities that do appear in John's experience, for example the specific pattern of oscillation that Pinky exhibits, are not visible in the wide sense.

However, there is another sense of visibility that conforms to our usage of the predicate 'made visible'. Consider night vision goggles again. Although surface heat is not visible, there is an intuitive sense in which the goggles make surface heat visible. But, unless there are two senses of visible, it would be a contradiction to say that something is made visible during a time period but is not visible during that period. Thus, there must be a sense of visibility that corresponds to 'made visible' and applies to items that are not visible in the narrow sense. ${ }^{27}$ We thus have two senses of visibility, a narrow sense that goes with the ordinary use of 'is visible' and a wide sense that goes with predicates such as 'is made visible'.

Let us reconsider Visibility in light of the distinction. The argument has two premises. First, something visually appears only if some of its visible qualities appear in visual experience. Second, the visible qualities of Pinky do not appear in John's visual experience. My contention is that there is no sense of visibility under which both of these premises are true. The premise that the visible qualities of Pinky do not appear in John's experience is true in the narrow sense because the shape and color of the silicon circuit do not appear in John's experience. However, this premise is false in the wide sense. For, there is no significant disanalogy between the case of Pinky and the case of heat. As we say that night vision goggles make surface heat visible, we can say that the envatment setup makes the oscillations in pinky visible. Thus, this premise is only true in the narrow sense of visibility. But the premise that something visually appears only if some of its visible qualities appear cannot be true in the narrow sense. Consider the goggles again. When you see an animal with night goggles, it visually appears. But none of its narrowly visible qualities visually appear. Therefore, the premise that something visually appears only if some of its visible qualities appear cannot be true in the narrow sense of visibility. I thus conclude that there is no sense of visibility under which both premises of Visibility are true. The argument can therefore be dismissed.

\footnotetext{
${ }^{26}$ By a normal perceiver I mean one whose perceptual system is not in any sense defective and by normal conditions of observation I mean those in which one's perceptual system is working unaided by external props or enhancements and the external conditions of observation are appropriate for the performance of one's perceptual system.

27 As one of the anonymous referees has aptly pointed out, under this narrow sense of visibility many properties could be made visible with the right goggles. I do not see this as a problematic implication.
} 
We have considered three different ways to support the intuition that Pinky does not appear in John's experience and concluded that all can be blocked. ${ }^{28}$ On the other hand, there is an intuitive sense in which Pinky seems to be the object of John's experience because John's experience counterfactually depends on some of the qualities of Pinky. ${ }^{29}$ We can conclude that the intuition that Pinky is the object of John's experience is on firmer ground than is often assumed. Anchoring is a promising strategy for resisting the idea that the experiences of brains in vats are m-hallucinations. If so, neural evidence in support of the possibility of envatment does not support the possibility of m-hallucinations because the idea that the experiences of envatted brains are hallucinations can be explained away by Anchoring.

\section{Dependence and Conceivability Arguments}

The arguments in the previous sections showed that the empirical evidence for the possibility of hallucinations is at best weak. But there are arguments in support of the possibility of hallucinations that are allegedly independent from empirical evidence. I noted an example of this type of argument that builds on the conceivability of a scenario in which a disembodied soul undergoes experiences that are phenomenally indistinguishable from my veridical perceptual experience of a pink elephant. The idea is that such cases are possible because they are conceivable, hence m-hallucinations are possible. My strategy is to show that arguments of this sort are not independent from the empirical arguments for the possibility of hallucination. We can conceive of such scenarios in so far as we presuppose either the actuality or the empirical possibility of m-hallucinations. Thus, the conceivability of space souls does not provide any independent evidence for their possibility. I call this strategy Dependence. If Dependence is successful then conceivability arguments for the possibility of m-hallucinations inherit the weakness of the corresponding empirical evidence.

The epistemic significance of conceivability is closely tied to issues about conceptual grasp. If one finds a proposition, p, conceivable because one's grasp of the relevant concepts involved in $\mathrm{p}$ is defective then p's conceivability is not a guide to its metaphysical possibility. One therefore needs to have a sufficient grasp of the concepts involved in a proposition before one could rely on the conceivability method to draw conclusions about metaphysical possibility. I shall call this the grasp condition. There could be disagreements about how to construe the sufficient grasp required. In its general form, however, the gasp condition does not seem to be controversial.

${ }^{28}$ My discussion here complements Ali 2017, §4. Ali's discussion is cashed out in terms of kinds (only objects that are of the same kind as the kind that an object appears to be in an experience can serve as the object of that experience), location (only objects that are at the perceived location that an object appears to be in an experience can serve as the object of that experience), properties (only objects that possess an adequate number of the properties that an object appears to have in an experience can serve as the object of that experience), and number (only a set of objects that has the same numerosity that a set of object appears to have in an experience can serve as the object of that experience). He does not discuss causal paths and visibility.

${ }^{29}$ Raleigh 2014 defends a similar claim by appealing to enactivist accounts of perception. 
The crucial concept involved in the conceivability of our scenario is the concept of experience. What is required to give one the sufficient grasp of the concept of experience? Here, one could distinguish between two senses of this question. One question has to do with what it is to be in the position of sufficient grasp. What does the minimally sufficient grasp of the concept of experience consist in? This is a constitutive question. Another question concerns what is conducive to putting one in the grasp position. What does it take to acquire the minimally sufficient grasp of the concept of experience? This is a causal question.

Acquiring a minimally sufficient grasp of the concept of experience of course requires the possession and the appropriate use of a set of capacities that are required for conceptual grasp in general. ${ }^{30}$ But, assuming that one is in possession of such general capacities and uses them properly, what else is causally required for a minimally sufficient grasp of the concept of experience? We can distinguish among different answers to this question.

One simple answer is that having a set of experiences that is sufficiently varied to serve as a generalization basis is sufficient to put one in a position of grasp. I call this answer the minimal empiricist answer. What counts as a sufficiently varied set of experiences? Would experiences from a single perceptual modality do? Do we need more? How varied within a single perceptual modality do the experiences need to be? Minimal empiricists could of course disagree about these issues. Nevertheless, we can distinguish a minimal empiricist view from other answers to the causal question that would require more than only a sufficiently varied set of experiences.

An alternative to minimal empiricism would draw its inspiration from Kripke's defense of a posteriori necessities. Kripke's defense of a posteriori necessities, did not lead him to deny that conceivability is a guide to possibility. Relatedly, he did not think that the scenario that one conceives of when one reports conceiving of water that is not $\mathrm{H} 2 \mathrm{O}$ is impossible. Rather, he held that in such cases we are conceiving of something water-like that is not $\mathrm{H} 2 \mathrm{O}$, but we mistakenly describe it as a scenario in which water is not $\mathrm{H} 2 \mathrm{O}$. The combination of accepting the conceivability method and a posteriori necessities suggests a Kripkean answer to the causal question about the sufficient grasp of concepts of natural kinds. On such an answer, in order to be put in the position of a sufficient grasp of the concept of water, a position where one can discover facts about water by reflecting on what is conceivable, one needs to somehow acquire knowledge of the underlying nature of water. An analogous line about experience would be that one must acquire sufficient knowledge of the natural facts that underlie experiences in order to be in a position to rely on conceivability to discover metaphysical facts about experience. ${ }^{31} \mathrm{I}$ would call this position the maximal empiricist position. ${ }^{32}$

30 What belongs to this list is of course a substantive question. But capacities such as recognitional capacities, associative capacities, attention, memory, abstraction, generalization, and reasoning are typical members.

31 This is not to say that Kripke would have accepted this Kripkean reply to the causal question about experience.

32 There are views in the ballpark of maximal empiricism that would replace the requirement for the acquisition of knowledge with a less demanding condition such as the acquisition of justified 
Maximal empiricism is not the only alternative to minimal empiricism. Drawing on Chalmers' metaphor of the Fall from Eden, we can answer the causal question in a way that denies minimal empiricism but does not go as far as embracing maximal empiricism. In "Perception and the Fall from Eden" Chalmers writes:

In the Garden of Eden, we had unmediated contact with the world. We were directly acquainted with objects in the world and with their properties. Objects were simply presented to us without causal mediation, and properties were revealed to us in their true intrinsic glory. ... But then there was a Fall. First, we ate from the Tree of Illusion. After this, objects sometimes seemed to have different colors and shapes at different times, even though there was reason to believe the object itself had not changed. So the connection between visual experience and the world became contingent: we could no longer accept that visual experience always revealed the world exactly as it is. ... We no longer live in Eden. Perhaps Eden never existed, and perhaps it could not have existed. But Eden still plays a powerful role in our perceptual experience of the world. At some level, perception represents our world as an Edenic world, populated by perfect colors and shapes, with objects and properties that are revealed to us directly. And even though we have fallen from Eden, Eden still acts as a sort of ideal that regulates the content of our perceptual experience. Or so I will argue. (Chalmers 2006)

Although this may not be its intended implication, the above passage suggests a picture according to which our belief to the effect that the connection between visual experiences and the world is contingent depends on having had illusory experiences and coming to know them as such. On this view, the reason that Edenic experiences are not sufficient to put us in a position to discover that the connection between experiences and reality is contingent is that in order to properly grasp the concept of experience one needs to have non-veridical experiences and come to know them as such. Since Edenic experiences are always veridical, they are not sufficient for grasping the concept of experience and would not put one in the position to discover metaphysical facts about experience through a priori reflection. ${ }^{33}$

We can distinguish between two different versions of the view by drawing on the distinction between illusions and hallucination. On one version, it is sufficient to eat from the tree of illusion: one needs to have illusory experiences and come to know them as such. On a more demanding version, one needs to eat from both the tree of illusion and the tree of hallucination: one needs to have had illusions and hallucinations and come to know both of them as such. We can regard these views as different versions of a moderate empiricist

beliefs. Everything that I say about maximal empiricism would apply to these views too. So, I shall not discuss them explicitly.

${ }^{33}$ I say this may not be the intended implication because on another reading the Fall does not improve one's grasp of the concept of experience. Rather, it is accompanied by a change in the nature of perceptual experience. 
answer to the causal question. I shall call them the illusion-based and the hallucinationbased versions of moderate empiricism respectively.

When one claims that one can conceive of space souls and concludes that space soul are metaphysically possible, one has committed to the following two claims: (a) one has satisfied the grasp condition that is, one is in a position where one has a sufficient grasp of the concept of experience, a position wherein what one conceives of about experiences implies what is metaphysically possible about them and (b) one can conceive of space souls in this position. My contention is that of the four positions outlined above only two, namely hallucination-based moderate empiricism and maximal empiricism would satisfy both (a) and (b). But these accounts presuppose either the actual occurrence or the empirical possibility of hallucinations. ${ }^{34}$

On the minimal empiricist view, having a sufficiently rich set of experiences that would serve as a generalization basis would give one the required grasp of the concept of experience. But it is, at best, questionable that simply having a set of experiences would render scenarios such as the space soul conceivable. The crucial reason for this is that perceptual experiences typically, and on some views essentially, have object-involving phenomenal character that is, they have the phenomenology of presenting external mindindependent objects to us. ${ }^{35}$ This, of course, does not logically entail that perceptual experiences involve objects. But in conjunction with minimal empiricism, this uncontroversial point seems to conflict with the conceivability of space soul scenarios. Since experiences typically have object-involving phenomenology, then it seems natural that the concept of experience that one would come to grasp only on the basis of having experiences, no matter how rich and varied they might be, has to be an object-involving concept. If all the bulls that one has observed seem to have horns and one's observations are all that is available to one as a basis for grasping the concept of a bull then, unless there is an alternative explanation, one's concept of a bull should somehow involve 'has a horn'. Analogously, if all the experiences that we have had seem to be object-involving then, in the absence of a good alternative explanation, your concept of experience has to be objectinvolving. But it's not clear whether there are any alternative possible explanations. If so, then the space soul scenario should not be conceivable for you. Obviously, one might have some auxiliary knowledge that would exclude 'is object-involving' from one's concept of experience. But a minimal empiricist view denies any requirement for such auxiliary knowledge. So, a minimal empiricist answer to the causal question cannot make sense of how space soul scenarios are conceivable.

\footnotetext{
${ }^{34}$ As one of the anonymous referees notes, here I'm ignoring non-empiricist answers to the causal question. This is because empiricism about the concept of experience has a high degree of intuitive plausibility. Moreover, to my knowledge, there is no empirical evidence in support of the claim that the concept of experience in human beings is innate.

35 This might be one sense in which our perceptual experiences are still Edenic. I do not think that there is much controversy about this, although those who wish to ground the phenomenal character of experience in its content might put the point in terms of the contents of perceptual experiences.
} 
Let us consider the moderate empiricist view. On the illusion-based version of this view, in order to satisfy the grasp condition one needs to have had illusions and come to know them as such. Could this move help the proponents of the space soul scenario? It might be tempting to answer this question positively. For, having illusions and coming to know them as such might provide an indirect route for the conceivability of space souls. One such indirect route could be that having illusions and coming to know them as such gives us reasons to regard experiences as appearances, where the concept of appearance is partially the concept of that which can come apart from the reality that it presents to us. But there is no inherent tension between the concept of appearance, of something that can come apart from reality, and the conceivability of the space soul scenario. Thus, it might seem that the illusion-based version of the moderate empiricist view can explain how we can conceive of space soul scenarios in a way that implies their metaphysical possibility. Therefore, eating from the tree of illusion helps us grasp that experience are appearances and this enables us to conceive of the space soul.

In response, we can distinguish between a weak and a strong concept of appearance. This distinction corresponds to the distinction between illusions and hallucinations. A weak appearance can misrepresent the qualities of the objects that it presents, but it cannot misrepresent their existence. A strong appearance can misrepresent both. Only the strong concept is compatible with the possibility of hallucinations. However, coming to form the concept of experience qua appearance as a result of having illusion and coming to know them as such only entitles us to the concept of appearance in the weak sense. This is because, by definition, illusions are experiences that have objects but misrepresent some of the properties of their object. Thus, the knowledge that an experience is an illusion does not give us any reasons to discount its phenomenology of object-involvingness. Therefore, the illusion-based version of moderate empiricism can only make sense of how we might come to grasp the concept of experience as an appearance in the weak sense. However, the concept of appearance in the weak sense is incompatible with the conceivability of space souls. Therefore, like minimal empiricism, the illusion-based version of moderate empiricism cannot make sense of how space souls are conceivable in a sense that implies their metaphysical possibility.

A hallucination-based version of moderate empiricism does not suffer from the above problem. For on this view, the causal conditions that are conducive to the satisfaction of the grasp condition entitle us to a concept of experience as appearance in the strong sense and the concept of appearance in the strong sense is compatible with the conceivability of space soul scenarios. Moderate empiricists can therefore explain how we might come to be in a position where we can conceive of space soul scenarios. However, the hallucinationbased version of moderate empiricism assumes that we have had hallucinations and have come to know them as such. Under this view, the conceivability of space souls does not provide a route to their possibility that is independent from the empirical evidence that hallucinations happen.

A similar point applies to strong empiricism under which coming to know the natural facts that underlie perceptual experience is conducive to the satisfaction of the grasp condition. If coming to know the natural facts that underlie perceptual experience is to enable us to conceive of space soul scenarios, it should do so by somehow enabling us to grasp the 
concept of experience as appearance in the strong sense. But it is unclear how knowing such facts could do so, unless knowing them enables us to see that object-less experiences are empirically possible. Strong empiricism might be able to make sense of how we can conceive of space soul scenarios, but it can only do so by relying on the empirical arguments of the sort that we discussed in the previous section.

Our discussion shows that the proponents of conceivability arguments face a dialectical dilemma. Absent the knowledge that one has had illusions or hallucinations, one is in a situation analogous to Eden in which one's concept of experience is a revelatory concept, the concept of experience as revealing something outside us, where revealing is only possible when something is there to be revealed. But the possibility of object-less hallucination scenarios is incompatible with a revelatory concept of experience. In order to be in a position to conceive of such scenarios, one therefore needs to have reasons to move beyond the revelatory concept of experience to the concept of experience as an appearance, as something whose constitution allows it to come apart from its object. This is exactly what having non-veridical experiences and having knowledge of them as such might provide. But simply having illusions and coming to know them as such will not be sufficient for the task, because it only entitles us to a weak concept of appearance. Thus, one is pushed toward either the hallucination-based version of moderate empiricism or maximal empiricism. However, embracing these more demanding versions of empiricism assumes that we have had hallucinations or that we have discovered the nature of the physical facts that underlie experience. However, this would threaten the position of the conceivability method as a dialectical device that is independent from empirical arguments and renders it vulnerable to the replies that we have discussed to the empirical arguments for the possibility of hallucinations.

\section{Conclusion}

This paper has explored four possible strategies for resisting the typical arguments for accepting the possibility of m-hallucinations. Displacing, Denial and Anchoring are responses to arguments that draw on empirical evidence, while Dependence blocks a priori arguments. A second upshot is that whether m-hallucinations are possible or not is still an open empirical question. Two sets of empirical questions are relevant here. The first has to do with descriptive phenomenology. What is the correct description of the phenomenology of those experiences that are sometimes assumed to be examples of hallucinations? Do these experiences have the assumed objectual phenomenal structure? Are they only pseudoperceptual or not? In so far as it is possible to answer these questions with the empirical methods, the debate partly hinges further empirical studies. The second set of questions has to do with the factors that are relevant to determining the perceptual objects of experiences. At the moment, there does not seem to be a consensus about a general account of perceptual objects. ${ }^{36}$ But given a specific account, the question as to whether some allegedly embedded hallucinations have existing perceptual objects or whether the states of the supercomputer can be regarded as the objects of the experiences of an envatted brain turn

\footnotetext{
${ }^{36}$ Most of the existing accounts are variants of the causal view defended in Grice 1961. See Jackson 1977, Lewis 1980, Noë 2003, and Tye 1982. For a review, see Arstila and Pihlainen 2009.
} 
into empirical questions. I therefore conclude that the debate over the possibility of hallucinations is to some extent an unresolved empirical debate. ${ }^{37}$

\section{References:}

Ali, R. (2018). Does Hallucinating Involve Perceiving? Philosophical Studies 175 (3):601-627.

Alston, W. (1999). Back to the Theory of Appearing. Philosophical Perspectives 13 (s13):181--203.

Arstila, V. \& Pihlainen, K. (2009). The Causal Theory of Perception Revisited. Erkenntnis 70(3):397 - 417.

Block, N. (1996). Mental Paint and Mental Latex. Philosophical Issues, (7):19-49.

Brewer, B. (2007). Perception and its Objects. Philosophical Studies, 132 (1): 87-97.

Brewer, B. (2011). Perception and its Objects. Oxford: Oxford University Press.

Byrne, A. \& Logue, H. (2008). Either/or. In Haddock, A. \& Macpherson, F., (eds.), Disjunctivism: Perception, Action, Knowledge. Oxford: Oxford University Press.

Burge, T. (2010). Origins of Objectivity. Oxford: Oxford University Press.

Campbell, J. (2002). Reference and Consciousness. Oxford: Oxford University Press.

Campbell, J. (2011). Berkeley's Puzzle. In Roessler, J., Lerman, H., \& Eilan, N. (eds.), Perception, Causation, and Objectivity. Oxford University Press.

Campbell, J. \& Cassam, Q. (2014). Berkeley's Puzzle: What Does Experience Teach Us.? Oxford: Oxford University Press.

Cassam,C. (201 1). Tackling Berkeley's Puzzle. In Roessler, J., Lerman, H., \& Eilan, N. (eds.), Perception, Causation, and Objectivity. Oxford: Oxford University Press.

Chalmers, D. (1996) The Conscious Mind. Oxford: Oxford University Press.

Chalmers, D. (2005). The Matrix as Metaphysics. In Grau, C., (eds.), Philosophers Explore the Matrix. Oxford: Oxford University Press.

37 This paper has benefitted from feedback from Katie Aulenbacher, John Bengson, Stephen Biggs, David Chalmers, Ranpal Dosanjh, Uriah Kriegel, Jason Leardi, Goeff Lee, Donnchadh O'Conaill, Yasser Pouresmail, William Robinson, Lawrence Shapiro, Alan Sidelle, Lindley Slipetz, Elliott Sober, Mike Titelbaum, Jonathan Simon, Jonathan Vandenhombergh, and the audience at the SPAWN 2015 10th Anniversary Workshop on Consciousness. 
Chalmers, D. (2006). Perception and the Fall from Eden. In Gendler T., \& Hawthorne, J., (eds.), Perceptual Experience. Oxford: Oxford University Press.

Coltheart, M. (2006). What has Functional Neuroimaging Told Us About the Mind (so far)? Cortex 42: 323-331.

Crane, T. (2006). Is There a Perceptual Relation? In Gendler T., \& Hawthorne, J., (eds.), Perceptual Experience. Oxford: Oxford University Press.

Dennett, D. (1976). Are Dreams Experiences? The Philosophical Review, 85 (2):151-171.

Fish, W. (2009). Perception, Hallucination, and Illusion. Oxford: Oxford University Press.

Gallagher, S. \& Zahavi, D. (2012). The Phenomenological Mind. London: Routledge.

Grice, H. P. (1961). The Causal Theory of Perception, Part I. Proceedings of the Aristotelian Society, $121: 121-152$.

Harley, T. (2004). Does Cognitive Neuropsychology Have a Future? Cognitive Neuropsychology, 21:3-16.

Hawthorne, J. \& Sturgeon, S. (2006). Disjunctivism. Proceedings of the Aristotelian Society, 80 (1):145-216.

Hinton, J. (1967). Visual Experiences. Mind 76:217-227.

Hinton, J. (1973). Experiences: An Inquiry into Some Ambiguities. Oxford: Clarendon Press.

Hering, J., (1947). Concerning Image, Idea, and Dream. Philosophy and Phenomenological Research, 8 (2): 188-205.

Hobson, J. (1988). The Dreaming Brain, New York: Basic Books.

Hobson, J., Pace-Schott E., \& Stickgold, R. (2000). Dreaming and the Brain. Toward a Cognitive Neuroscience of Conscious States. Behavioral and Brain Sciences, 23: 793-842.

Ichikawa, J. (2008). Scepticism and the Imagination Model of Dreaming. The Philosophical Quarterly, 58 (232): 519-527.

Jackson, Frank (1977). Perception: A Representative Theory. Cambridge: Cambridge University Press.

James, W. (1890). The Principles of Psychology, Volume Two. New York: Dover Publications (1950).

Johnston, Mark. (2004). The Obscure Object of Hallucination. Philosophical Studies 120 (1- 
3):113-183.

Kant, Immanuel (1998). Critique of Pure Reason (translated and edited by Paul Guyer \& Allen W. Wood). Cambridge.

Klein, C. (2010a). Images Are Not the Evidence in Neuroimaging. British fournal of Philosophy of Science, 61: 265-278.

Klein, G. (2010b). Philosophical Issues in Neuroimaging. Philosophy. Compass, 5: 186-198.

Kriegel, U. (2013). Two Notions of Mental Representation. In Kriegel, U. (ed.), Current Controversies in Philosophy of Mind. New York: Routledge

Langsam, H. (1997). The Theory of Appearing Defended. Philosophical Studies, 87 (1):3359.

Levine, J. (2010). Demonstrative Thought. Mind \& Language, 25 (2):169-195

Martin, M.G.F. (2002). The Transparency of Experience. Mind and Language, 17:376-425.

Lewis, D. (1980). Veridical Hallucination and Prosthetic Vision. Australasian fournal of Philosophy, 58:239-249.

Malcolm, N., 1956. Dreaming and Skepticism. The Philosophical Review, 65 (1):14-37.

Martin, M. (2004). The Limits of Self-Awareness. Philosophical Studies, 120:37-89.

Masrour (2013). Phenomenal Objectivity and Phenomenal Intentionality: In Defense of a Kantian Account. In Kriegel, U., (ed.,) Phenomenal Intentionality, Oxford: Oxford University Press.

McDowell, J. (1982). Criteria, Defeasibility and Knowledge. Proceedings of the British Academy, 68:455-479.

McDowell, J. (1994). Mind and World. Cambridge: Harvard University Press.

McDowell, J. (2008). The Disjunctive Conception of Experience as Material for a Transcendental Argument. In F. Macpherson \& A. Haddock (eds.), Disjunctivism: Perception, Action, Knowledge. Oxford: Oxford University Press.

McGinn, C. (2004). Mindsight: Image, Dream, Meaning, Cambridge MA \& London: Harvard University Press.

Noë, A. (2003). Causation and Perception: The Puzzle Unravelled. Analysis 63 (2): 93-100.

Noë, A. (2004). Action in Perception. Cambridge: MIT Press. 
Raleigh, T. (2014). A New Approach to 'Perfect' Hallucinations. Fournal of Consciousness Studies 21 (11-12): 81-110.

Revonsuo, A. (2006). Inner Presence: Consciousness as a Biological Phenomenon, Cambridge, MA \& London: MIT Press.

Rey, G. (2005). Explanation, not Experience: Commentary on John Campbell, Reference and Consciousness. Philosophical Studies, 126 (1):131-143.

Sartre, J.P. (1940)

Rosen, M.G. (2013). What I Make Up When I Wake up: Anti-Experience Views and Narrative Fabrication of Dreams. Frontiers in Psychology, 4 (online).

Siegel, S. (2004). Indiscriminability and the Phenomenal. Philosophical Studies 120 (1-3):91112.

Siegel, S. (2006). Subject and Object in the Contents of Visual Experience. The Philosophical Review, 115 (3): 355-388.

Snowdon, P. (1980). Perception, Vision, and Causation. Proceedings of the Aristotelian Society 81:175-92.

Soteriou, M. The Disjunctive Theory of Perception, In Zalta E., (ed.), The Stanford Encyclopedia of Philosophy. (online)

Soteriou, M. (2016). Disjunctivism. London: Routledge.

Sturgeon, S. (1998). Visual experience. Proceedings of the Aristotelian Society 72 (2):179-200.

Sturgeon, Scott (2008). Disjunctivism About Visual Experience. In Adrian Haddock \& Fiona Macpherson (eds.), Disjunctivism: Perception, Action, Knowledge. Oxford: Oxford University Press.

Schwitzgebel, E. (2011). Perplexities of Consciousness. Cambridge: MIT Press.

Thompson, E. \& Cosmelli, D. (2011). Brain in a Vat or Body in a World?: Brainbound versus Enactive Views of Experience. Philosophical Topics 39 (1):163-180.

Tye, M. (1982). A Causal Analysis of Seeing. Philosophy and Phenomenological Research 42: 311-325.

Williamson, T. (2000). Knowledge and its Limits. Oxford: Oxford University Press.

Wright, C. (2002). (Anti-)sceptics Simple and Subtle: G. E. Moore and John McDowell. Philosophy and Phenomenological Research 65 (2):330-348. 
Wright, C. (2008). Comment on John McDowell's "The Disjunctive Conception of Experience as Material for a Transcendental Argument". In Haddock, A. \& Macpherson, F., (eds.), Disjunctivism: Perception, Action and Knoweledge. Oxford: Oxford University Press. 